\title{
The value of serum amylase and drain fluid amylase to predict postoperative pancreatic fistula after pancreatoduodenectomy: a retrospective cohort study
}

\author{
Jelle C. van Dongen ${ }^{1}$ (D) - Steven Merkens ${ }^{1} \cdot$ M. Hossein Aziz ${ }^{1}$ - Bas Groot Koerkamp ${ }^{1} \cdot$ Casper H. J. van Eijck ${ }^{1,2}$
}

Received: 9 February 2021 / Accepted: 6 May 2021 / Published online: 14 May 2021

(C) The Author(s) 2021

\begin{abstract}
Purpose Serum and drain amylase have been identified as important predictors of postoperative pancreatic fistula (POPF) and might be useful to guide postoperative drain management after pancreatoduodenectomy. We aimed to determine and compare the value of serum amylase and drain fluid amylase to predict postoperative pancreatic fistula after pancreatoduodenectomy.

Methods This retrospective cohort study included patients after pancreatoduodenectomy from 2012 to 2019. The primary endpoint of our study was grade B/C POPF. Serum amylase on postoperative day 1 (SA-1) and drain fluid amylase on postoperative day 2 (DFA-2) were analyzed.

Results A total of 92 of 437 patients (21.1\%) developed a grade B/C POPF. SA-1 was higher in patients who developed a grade B/C POPF (336 U/L vs. $97 \mathrm{U} / \mathrm{L}, \mathrm{p}<0.001$ ). Similarly, DFA-2 was higher in patients who developed a grade B/C POPF (1764 U/L vs. $78 \mathrm{U} / \mathrm{L}, \mathrm{p}<0.001$ ). SA-1 and DFA-2 had similar predictive accuracy (AUC: 0.82 vs. 0.85 , respectively, $\mathrm{p}=0.329$ ). Patients with SA-1 $<100 \mathrm{U} / \mathrm{L}(\mathrm{n}=178)$ had a risk of $2.2 \%$ of developing grade $\mathrm{B} / \mathrm{C}$ POPF, compared to $38.2 \%$ in patients with SA-1 $>100$ $\mathrm{U} / \mathrm{L}(\mathrm{n}=207)$. Patients with DFA-2 $<100 \mathrm{U} / \mathrm{L}(\mathrm{n}=141)$ had a risk of $0 \%$ of developing grade $\mathrm{B} / \mathrm{C}$ POPF, compared to $36.2 \%$ in patients with DFA-2>100 U/L ( $\mathrm{n}=196)$. SA-1 and DFA-2 were strongly associated at a cut-off of $100 \mathrm{U} / \mathrm{L}(\mathrm{p}<0.001,89 \%$ concordance rate).

Conclusion Postoperative serum and drain amylase values below $100 \mathrm{U} / \mathrm{L}$ both effectively rule out POPF after pancreatoduodenectomy. The advantage of serum amylase measurement is that it can be used in patients who are managed without surgical drains.
\end{abstract}

Keywords Pancreatoduodenectomy $\cdot$ Amylase $\cdot$ Pancreatic fistula

\section{Introduction}

Postoperative pancreatic fistula (POPF) is the major determinant of morbidity after pancreatoduodenectomy $[1,2]$. POPF can result in hemorrhage, abdominal sepsis, multisystem organ failure, and death $[1,3]$. In an attempt to mitigate the effects of POPF, the intra-operative placement of intraperitoneal drains is commonly done, even though still controversial [4-6]. Studies suggest that early drain removal $(\leq$

Casper H. J. van Eijck

c.vaneijck@erasmusmc.nl

1 Department of Surgery, Erasmus MC Cancer Institute, Rotterdam, The Netherlands

2 Erasmus University Medical Center, Rg-231, Doctor Molewaterplein 40, 3015, GD Rotterdam, The Netherlands postoperative day (POD) 3) in low risk patients is associated with a decreased incidence of POPF and abdominal complications and reduced healthcare utilization costs compared to late drain removal (after POD 3) [7-9]. However, in current practice, a wide variation in postoperative drain management still exists [9].

Recently, postoperative serum amylase (SA) demonstrated to be an adequate predictor of POPF [10-14]. Therefore, SA might be useful in the guidance of drain removal. The removal of postoperative drains is generally based on the drain fluid amylase (DFA) output [7-9, 15-18]. Recent studies advocate a DFA threshold of 90-100 U/L for drain removal [16-18], remarkably lower than the $5000 \mathrm{U} / \mathrm{L}$ used in a prior randomized controlled trial [7]. Moreover, combining SA and DFA might improve prediction of POPF; however, this has only been studied in small series $[12,19]$. Finally, SA can also predict POPF in patients who are managed without surgical drains. 
Therefore, we aimed to determine and compare the value of serum amylase and drain fluid amylase to predict postoperative pancreatic fistula after pancreatoduodenectomy. Also, we aimed to establish clinically useful threshold values for serum amylase and drain fluid amylase.

\section{Methods}

The Medical Ethical Review Committee of the Erasmus MC in Rotterdam, the Netherlands, approved this study and waived the need for informed consent (MEC-2018-1176).

\section{Study population}

This retrospective cohort study included consecutive patients who underwent a pancreatoduodenectomy in the Erasmus MC from January 2012 to December 2019. Patients with additional concurrent resection, such as partial liver resections and hemicolectomies, were excluded.

\section{Data collection}

Demographics, clinical characteristic, laboratory data, and operation details were extracted from prospectively maintained databases or from systematically reviewed patient charts. The diameter of the pancreatic duct was measured on preoperative computed tomography (CT) scan at the line of pancreatic transection anterior to the portal vein. Pancreatic texture was determined intra-operatively by the surgeon (soft/normal or hard). High-risk pathology was defined as anything other than pancreatic adenocarcinoma or chronic pancreatitis [1].

\section{Surgical and postoperative procedures}

Blood serum laboratory measurements were routinely performed on POD 1, 3, and 5. SA was collected on POD 1 (SA-1) and POD 3 (SA-3) and DFA on POD 2 (DFA-2). The reference value of SA in our center was 0-52 U/L. In case of two DFA-2 values, the highest value was collected.

Both pylorus-ring resection and pylorus-preserving pancreatoduodenectomy were performed. The standard method of reconstruction was a pancreaticojejunostomy with duct-to-mucosa reconstruction. Pancreatic stents were not routinely placed. Intra-abdominal drains were routinely placed intra-operatively. Non-vacuuming silicon drains were placed in the proximity of the pancreaticojejunostomy and/or hepaticojejunostomy, most commonly dorsal of these anastomoses in the sub-hepatic space. Early postoperative drain removal was generally based on DFA and bilirubin levels on POD 2.

\section{Surgical outcomes}

The primary endpoint of this study was the incidence of grade B/C POPF according to the 2016 International Study Group for Pancreatic Fistula definition [20]. Other surgical outcomes included delayed gastric emptying [21], post-pancreatectomy hemorrhage [22], and major complications defined as grade $\geq$ $3 \mathrm{a}$ according to the Clavien-Dindo classification [23].

\section{Statistical analysis}

Continuous variables were expressed as a mean \pm standard deviation or as a median \pm interquartile range, depending on their distribution. For univariable analysis, continuous variables were compared using a T-test or a Mann-Whitney U test. Categorical variables were assessed using the chi-squared test or Fisher's exact test (when a category includes $<5$ patients). Diagnostic properties were determined based on receiver operating characteristic (ROC) curves. Based on the poor diagnostic value of SA-3, further analyses were limited to SA-1 and DFA-2. In the subset of patients with elevated SA-1 and DFA-2, univariable logistic regression was performed to determine odds ratios. A flowchart was constructed to evaluate the clinical value of combining SA1 and DFA-2. Two-sided p-values $<0.05$ were considered statistically significant. $\mathrm{R}$ statistical software (version 3.4.3; www.r-project.org) was used for all statistical analyses.

\section{Results}

\section{Study population}

The cohort consisted of 437 patients who underwent a pancreatoduodenectomy. Twenty patients were excluded due to concurrent other organ resections. In 357 patients (81.7\%), a pancreatoduodenectomy with pylorus-ring resection was performed and in 80 patients $(18.3 \%)$ a pylorus-preserving pancreatoduodenectomy. Thirty-three patients $(7.6 \%)$ underwent preoperative chemoradiotherapy, and 13 patients (3.0\%) underwent chemotherapy. Thirteen patients $(3.0 \%)$ did not have a drain placed intra-operatively.

The most common pathological diagnoses included 169 pancreatic adenocarcinoma (39.0\%), 51 distal cholangiocarcinoma $(12.0 \%), 41$ intraductal papillary mucinous neoplasms (IPMN) (9.4\%), and 26 duodenal cancer (6.0\%). Ninety-two patients $(21.1 \%)$ developed a grade $\mathrm{B} / \mathrm{C}$ POPF.

In univariable analysis, grade $\mathrm{B} / \mathrm{C}$ POPF was associated with diabetes mellitus, neoadjuvant therapy, high-risk pathology, diameter of pancreatic duct, pancreatic texture, and intraoperative blood loss (Table 1). 
Table 1 Patient characteristics stratified by postoperative pancreatic fistula ${ }^{\dagger}$

\begin{tabular}{|c|c|c|c|c|}
\hline & $\begin{array}{l}\text { Overall } \\
(\mathrm{n}=437)\end{array}$ & $\begin{array}{l}\text { No POPF } \\
(\mathrm{n}=345)\end{array}$ & $\begin{array}{l}\mathrm{POPF}^{\dagger} \\
(\mathrm{n}=92)\end{array}$ & p-value \\
\hline Age & $68(59-73)$ & $68(59-73)$ & $68(58-75)$ & 0.429 \\
\hline Male sex & $244(56 \%)$ & $189(55 \%)$ & $55(60 \%)$ & 0.391 \\
\hline BMI & $24.5(22.3-26.9)$ & $24.3(22.3-26.6)$ & $25.1(22.4-27.7)$ & 0.068 \\
\hline ASA status $3-4$ & $119(27 \%)$ & $99(29 \%)$ & $20(22 \%)$ & 0.169 \\
\hline Diabetes mellitus & $113(26 \%)$ & $100(29 \%)$ & $13(14 \%)$ & 0.004 \\
\hline Neoadjuvant therapy & $47(11 \%)$ & $44(13 \%)$ & $3(3.3 \%)$ & 0.009 \\
\hline Type neoadjuvant therapy & & & & 0.016 \\
\hline No neoadjuvant therapy & $390(89 \%)$ & $301(87 \%)$ & $89(97 \%)$ & \\
\hline Chemoradiotherapy & $33(7.6 \%)$ & $32(9.3 \%)$ & $1(1.1 \%)$ & \\
\hline Chemotherapy & $13(3.0 \%)$ & $11(3.2 \%)$ & $2(2.2 \%)$ & \\
\hline Radiotherapy & $1(0.2 \%)$ & $1(0.3 \%)$ & $0(0 \%)$ & \\
\hline High-risk pathology & $243(56 \%)$ & $166(48 \%)$ & $77(84 \%)$ & $<0.001$ \\
\hline Malignant pathology & $333(76 \%)$ & $263(76 \%)$ & $70(76 \%)$ & 0.941 \\
\hline Preoperative biliary drainage & $267(63 \%)$ & $214(64 \%)$ & $53(58 \%)$ & 0.341 \\
\hline Pancreatic duct diameter (mm) & $3(2.0-6.0)$ & $4(2-6)$ & $2(1-4)$ & $<0.001$ \\
\hline Robot-assisted procedure & $100(23 \%)$ & $75(22 \%)$ & $25(27 \%)$ & 0.270 \\
\hline Soft/normal pancreatic texture & $150(47 \%)$ & $95(38 \%)$ & $55(79 \%)$ & $<0.001$ \\
\hline Intra-operative blood loss (ml) & $730(400-1300)$ & $700(400-1300)$ & $964(500-1500)$ & 0.044 \\
\hline CRP on POD $3(\mathrm{mg} / \mathrm{L})$ & $206(121-294)$ & $186(109-258)$ & $307(214-352)$ & $<0.001$ \\
\hline Days to drain removal in days & $4(3-6)$ & $3(3-5)$ & $5(3-18)$ & $<0.001$ \\
\hline Length of hospital stay & $13(9-23)$ & $11(8-16.5)$ & $31(20.5-53)$ & $<0.001$ \\
\hline Major morbidity (Clavien-Dindo $\geq$ grade 3 ) & $173(40 \%)$ & $87(25 \%)$ & $86(93 \%)$ & $<0.001$ \\
\hline Postoperative mortality & $16(3.7 \%)$ & $8(2.3 \%)$ & $8(8.7 \%)$ & 0.008 \\
\hline Delayed gastric emptying grade $\mathrm{B} / \mathrm{C}^{\mathrm{qI}}$ & $104(24 \%)$ & $51(15 \%)$ & $53(58 \%)$ & $<0.001$ \\
\hline Postpancreatectomy hemorrhage grade $\mathrm{B} / \mathrm{C}^{¥}$ & $39(8.9 \%)$ & $15(4.3 \%)$ & $24(26 \%)$ & $<0.001$ \\
\hline Readmittance due to surgical complications & $75(17 \%)$ & $52(15 \%)$ & $23(26 \%)$ & 0.018 \\
\hline
\end{tabular}

${ }^{\dagger}$ Grade B/C postoperative pancreatic fistula according to the International Study Group for Pancreatic Surgery criteria

${ }^{\star}$ High-risk pathology included all pathological diagnosis except pancreatic ductal adenocarcinoma and chronic pancreatitis

${ }^{\text {II }}$ Grade B/C delayed gastric emptying according to the International Study Group for Pancreatic Surgery criteria

${ }^{¥}$ Grade B/C post-pancreatectomy hemorrhage according to the International Study Group for Pancreatic Surgery criteria

$P O P F$ postoperative pancreatic fistula, $C R P$ C-reactive protein, $P O D$ postoperative day

\section{Serum amylase and drain fluid amylase}

SA-1 was available in 385 patients $(88.1 \%)$ and SA-3 in 340 patients $(77.8 \%)$. Median SA-1 was significantly higher in patients who developed POPF compared to patients who did not develop POPF (336 U/L vs. $97 \mathrm{U} / \mathrm{L}, \mathrm{p}<0.001$ ), with an AUC of 0.82 (95\% CI: $0.78-0.86, \mathrm{p}<0.001)$. Median SA-3 was also significantly higher in patients who developed POPF (55 U/L vs. $25 \mathrm{U} / \mathrm{L}, \mathrm{p}<0.001$ ), with an AUC of 0.75 (95\% CI: $0.70-0.81$ ). A higher risk of POPF is observed over the increasing quartiles of SA-1 (1.0\% vs. $4.2 \%$ vs. $36.5 \%$ vs. $44.7 \%$, respectively).

DFA-2 was available in 338 patients $(77.3 \%)$. Median DFA-2 was significantly higher in patients who developed POPF compared to patients who did not develop POPF
(1764 U/L vs. $78 \mathrm{U} / \mathrm{L}, \mathrm{p}<0.001)$, with an AUC of 0.85 (95\% CI: $0.81-0.89, \mathrm{p}<0.001$ ). The AUCs of SA-1 and DFA-2 did not differ significantly $(\mathrm{p}=0.329)$. Similarly, DFA-2 shows a rising incidence of POPF over the increasing quartiles $(0 \%$ vs. $9.5 \%$ vs. $25.0 \%$ vs. $50.0 \%$, respectively). No differences were observed between patients with and without available SA-1 or DFA-2 (Supplemental table 1). Both biomarkers showed a nonlinear relationship with POPF (Supplemental figure 1).

Table 2 shows the median SA- 1 and DFA- 2 across patient characteristics. SA-1 and DFA-2 were both associated with preoperative chemoradiotherapy, diameter of the pancreatic duct, pancreatic texture, high-risk pathology (i.e., other than pancreatic cancer or chronic pancreatitis), and malignant pathology. 
Figure 1 displays the diagnostic properties of SA-1 and DFA-2 at different thresholds. Sensitivity remains close to $100 \%$ for both SA-1 and DFA-2 up to a cut-off value of 100 U/L. Patients with SA- $1<100 \mathrm{U} / \mathrm{L}(\mathrm{n}=178)$ had a $2.2 \%$ risk on grade $\mathrm{B} / \mathrm{C}$ POPF, compared to $38.2 \%$ in patients with SA-1 $>100 \mathrm{U} / \mathrm{L}(\mathrm{n}=207)$. The four patients with POPF and SA-1 $<100 \mathrm{U} / \mathrm{L}$ experienced a grade B POPF due to radiological drainage of an amylase-rich fluid collection. Likewise, patients with DFA- $2<100 \mathrm{U} / \mathrm{L}(\mathrm{n}=141)$ had a $0 \%$ risk on grade $\mathrm{B} / \mathrm{C}$ POPF, compared to $36.2 \%$ in patients with DFA-2 $>100$ $\mathrm{U} / \mathrm{L}(\mathrm{n}=196)$. Patients with elevated SA-1 or DFA-2 experienced more postoperative complications had a longer length of hospital stay, and drains were removed later (Table 3).
In the subset of patients with SA-1 and DFA-2 $>100 \mathrm{U} / \mathrm{L}$ $(\mathrm{n}=154)$, only intra-operative blood loss $(\mathrm{p}=0.006)$ and $\mathrm{C}$ reactive protein $(\mathrm{CRP})$ on POD $3(\mathrm{p}<0.001)$ were associated with POPF in univariable analysis (Supplemental table 2). CRP on POD 3 demonstrated an area-under-the-curve of $0.737(0.652-0.822)$ in patients with SA-1 and DFA-2 > $100 \mathrm{U} / \mathrm{L}$.

SA-1 and DFA-2 at a cut-off of $100 \mathrm{U} / \mathrm{L}$ were strongly associated $(\mathrm{p}<0.001)$, as there was concordance between the two parameters in $89 \%$ of the patients. Of patients with SA-1 $<100 \mathrm{U} / \mathrm{L}, 113(84.3 \%)$ also had a DFA-2 $<100$ U/L. A flowchart (Fig. 2) was constructed using a SA-1 threshold of $100 \mathrm{U} / \mathrm{L}$. The patients with

Table 2 Median serum amylase on postoperative day 1 and median drain fluid amylase on postoperative day 2 stratified by patient characteristics

\begin{tabular}{|c|c|c|c|c|}
\hline & $\begin{array}{l}\text { Median (IQR) serum amylase } \\
\text { on POD } 1(\mathrm{U} / \mathrm{L})\end{array}$ & p-value & $\begin{array}{l}\text { Median (IQR) drain amylase } \\
\text { on POD } 2(\mathrm{U} / \mathrm{L})\end{array}$ & p-value \\
\hline \multicolumn{5}{|l|}{ Age } \\
\hline $\begin{array}{l}<70 \\
\geq 70\end{array}$ & $\begin{array}{l}121(50-335) \\
117(56-322)\end{array}$ & 0.682 & $\begin{array}{l}162(33-1304) \\
163(35-803)\end{array}$ & 0.753 \\
\hline \multicolumn{5}{|l|}{ Gender } \\
\hline $\begin{array}{l}\text { Male } \\
\text { Female }\end{array}$ & $\begin{array}{l}128(56-308) \\
128(56-308)\end{array}$ & 0.481 & $\begin{array}{l}160(36-1062) \\
190(34-1498)\end{array}$ & 0.494 \\
\hline \multicolumn{5}{|c|}{ Body mass index } \\
\hline $\begin{array}{l}<25 \\
\geq 25\end{array}$ & $\begin{array}{l}103(49-310) \\
142(56-345)\end{array}$ & 0.113 & $\begin{array}{l}114(27-706) \\
270(61-1787)\end{array}$ & $<0.001$ \\
\hline \multicolumn{5}{|l|}{ ASA score } \\
\hline $\begin{array}{l}1-2 \\
3-4\end{array}$ & $\begin{array}{l}125(53-337) \\
105(50-286)\end{array}$ & 0.521 & $\begin{array}{l}179(35-1473) \\
134(34-561)\end{array}$ & 0.362 \\
\hline \multicolumn{5}{|c|}{ Preoperative biliary drainage } \\
\hline $\begin{array}{l}\text { No } \\
\text { Yes }\end{array}$ & $\begin{array}{l}160(56-364) \\
101(52-293)\end{array}$ & 0.203 & $\begin{array}{l}270(44-1584) \\
125(32-1090)\end{array}$ & 0.051 \\
\hline \multicolumn{5}{|c|}{ Preoperative chemoradiotherapy } \\
\hline $\begin{array}{l}\text { No } \\
\text { Yes }\end{array}$ & $\begin{aligned} 142 & (57-354) \\
55 & (28-76)\end{aligned}$ & $<0.001$ & $\begin{array}{l}221(41-1420) \\
20(12-67)\end{array}$ & $<0.001$ \\
\hline \multicolumn{5}{|c|}{ Diameter pancreatic duct } \\
\hline $\begin{array}{l}\leq 3 \mathrm{~mm} \\
>3 \mathrm{~mm}\end{array}$ & $\begin{array}{r}237(79-502) \\
72(36-163)\end{array}$ & $<0.001$ & $\begin{array}{l}528(104-2086) \\
49(20-270)\end{array}$ & $<0.001$ \\
\hline \multicolumn{5}{|c|}{ Pancreatic texture } \\
\hline $\begin{array}{l}\text { Soft/normal } \\
\text { Hard/fibrotic }\end{array}$ & $\begin{array}{l}258(111-545) \\
61(31-120)\end{array}$ & $<0.001$ & $\begin{array}{l}733(162-2767) \\
39(20-155)\end{array}$ & $<0.001$ \\
\hline \multicolumn{5}{|c|}{ High-risk pathology ${ }^{\dagger}$} \\
\hline $\begin{array}{l}\text { No } \\
\text { Yes }\end{array}$ & $\begin{array}{r}73(36-142) \\
220(71-467)\end{array}$ & $<0.001$ & $\begin{array}{c}54(21-253) \\
454(76-1914)\end{array}$ & $<0.001$ \\
\hline \multicolumn{5}{|c|}{ Malignant pathology } \\
\hline $\begin{array}{l}\text { No } \\
\text { Yes }\end{array}$ & $\begin{array}{r}212(75-509) \\
93(49-270)\end{array}$ & $<0.001$ & $\begin{array}{l}672(63-1996) \\
133(32-769)\end{array}$ & 0.004 \\
\hline \multicolumn{5}{|c|}{ Intra-operative blood loss } \\
\hline $\begin{array}{l}\leq 1500 \mathrm{ml} \\
>1500 \mathrm{ml}\end{array}$ & $\begin{array}{l}115(48-315) \\
140(61-429)\end{array}$ & 0.038 & $\begin{array}{l}162(33-1231) \\
175(35-989)\end{array}$ & 0.873 \\
\hline
\end{tabular}

${ }^{\dagger}$ High-risk pathology included all pathological diagnosis except pancreatic ductal adenocarcinoma and chronic pancreatitis

$P O D$ postoperative day, $I Q R$ interquartile range 
Table 3 Surgical outcomes of patients by serum amylase on postoperative day 1 and drain fluid amylase on postoperative day 2

\begin{tabular}{|c|c|c|c|c|c|c|}
\hline & $\begin{array}{l}\text { SA- } 1<100 \\
N=178\end{array}$ & $\begin{array}{l}\text { SA- } 1>100 \\
N=207\end{array}$ & p-value & $\begin{array}{l}\text { DFA- } 2<100 \\
N=141\end{array}$ & $\begin{array}{l}\text { DFA-2 }>100 \\
N=197\end{array}$ & p-value \\
\hline Intra-operative blood loss & $685(315-1162)$ & $800.0(500-1400)$ & 0.045 & $700(400-1300)$ & $730.0(400-1375)$ & 0.869 \\
\hline C-reactive protein $(\mathrm{mg} / \mathrm{L})$ on postoperative day 3 & $159(99-246)$ & $244(158-325)$ & $<0.001$ & $141(88-228)$ & $231(151-316)$ & $<0.001$ \\
\hline Days to drain removal in days & $3(3-4)$ & $4(3-7)$ & $<0.001$ & $3(3-5)$ & $4(3-6)$ & 0.004 \\
\hline Length of hospital stay & $11(8-17)$ & $16(10-31)$ & $<0.001$ & $11(8-18)$ & $15(10-30)$ & $<0.001$ \\
\hline Major morbidity (Clavien-Dindo > grade 2) & $43(24 \%)$ & $107(52 \%)$ & $<0.001$ & $36(26 \%)$ & $93(47 \%)$ & $<0.001$ \\
\hline Postoperative mortality & $3(1.7 \%)$ & $9(4.3 \%)$ & 0.134 & $4(2.8 \%)$ & $4(2.0 \%)$ & 0.724 \\
\hline Postoperative pancreatic fistula ${ }^{\dagger}$ & $4(2.2 \%)$ & $79(38 \%)$ & $<0.001$ & $0(0 \%)$ & $72(37 \%)$ & $<0.001$ \\
\hline Delayed gastric emptying grade $\mathrm{B} / \mathrm{C}^{\mathrm{II}}$ & $27(15 \%)$ & $65(31 \%)$ & $<0.001$ & $19(13 \%)$ & $63(32 \%)$ & $<0.001$ \\
\hline Postpancreatectomy hemorrhage grade $\mathrm{B} / \mathrm{C}^{¥}$ & $5(2.8 \%)$ & $25(12 \%)$ & $<0.001$ & $4(2.8 \%)$ & $26(13 \%)$ & $<0.001$ \\
\hline Readmittance due to surgical complications & $29(16 \%)$ & $38(19 \%)$ & 0.549 & $22(16 \%)$ & $39(20 \%)$ & 0.306 \\
\hline
\end{tabular}

${ }^{\dagger}$ Grade B/C postoperative pancreatic fistula according to the International Study Group for Pancreatic Surgery criteria

${ }^{\text {II }}$ Grade B/C delayed gastric emptying according to the International Study Group for Pancreatic Surgery criteria

${ }^{¥}$ Grade B/C post-pancreatectomy hemorrhage according to the International Study Group for Pancreatic Surgery criteria

SA-1 $>100 \mathrm{U} / \mathrm{L}$ were split in four groups based on their DFA-2 level. Twelve patients (7.2\%) had a DFA-2 < $100 \mathrm{U} / \mathrm{L}$. All remaining patients had a risk of more than $28 \%$ of developing POPF.

\section{Discussion}

In this study, serum amylase on postoperative day 1 and drain fluid amylase on postoperative day 2 both effectively rule out grade $\mathrm{B} / \mathrm{C}$ postoperative pancreatic fistula. Both biomarkers had a high negative predictive value, allowing for safe early drain removal in a subset of the patients. Based on our data, we propose a threshold of $100 \mathrm{U} / \mathrm{L}$ for both SA-1 and DFA-2. DFA-2 demonstrated little clinical value in addition to SA-1 in the identification of patients eligible for early removal of postoperative drains due to the strong relation between the two biomarkers.

Postoperative pancreatitis, defined as serum hyperamylasemia, has proven to be an important determinant in the development of POPF [10-14]. It is hypothesized that postoperative inflammation of pancreatic tissue causes impaired healing of the pancreatojejunal anastomosis, resulting in leakage of enzymatic fluid in the abdominal cavity. We found that patients with POPF had higher CRP levels on POD 3, indeed suggesting early inflammatory processes [24]. Another hypothesis is that the peritoneal membrane reuptakes leaked amylase-rich fluid from the abdominal cavity increasing serum amylase levels. The absence of serum hyperamylasemia $(<100 \mathrm{U} / \mathrm{L})$ was associated with a $2.2 \%$ risk of developing POPF, compared to $38.2 \%$ in patients with SA-1 $>100$ U/L (PPV $=38.2 \%$, NPV $=97.8 \%)$. Similarly, a recent retrospective study demonstrated a high negative predictive value for SA using Connor's cut-off for SA (SA < $50 \mathrm{U} / \mathrm{L}, \mathrm{PPV}=36.2 \%, \mathrm{NPV}=95.3 \%)$ and the Atlanta criteria $(\mathrm{SA}<150 \mathrm{U} / \mathrm{L}, \mathrm{PPV}=53.8 \%, \mathrm{NPV}=88.2 \%)$ in 292 patients [14]. In addition, Palani velu et al. recommended an optimal threshold of SA on the night after pancreatoduodenectomy of $130 \mathrm{U} / \mathrm{L}(\mathrm{PPV}=36.7 \%, \mathrm{NPV}=88.8 \%)$ in 185 patients [11]. Kuhlbrey et al. also demonstrated a high negative predictive value of SA- $1<159 \mathrm{U} / \mathrm{L}(\mathrm{PPV}=48 \%$, NPV $=92.2 \%)$ in 561 patients after pancreatoduodenectomy.[13] Based on our data, a threshold of $100 \mathrm{U} / \mathrm{L}$ for safe drain removal is optimal on POD 1.

Drain fluid amylase is a well-established predictor of POPF [15-18]. The randomized controlled trial (RCT) by Bassi et al. demonstrated that early drain removal (POD 3) was associated with a reduced rate of postoperative complications compared to late drain removal (POD 5 or beyond) [7]. In this trial, drain removal was based on a threshold value of DFA $<5000 \mathrm{U} / \mathrm{L}$ on POD 1; however, our study suggests that a lower threshold might be more suitable. Patients with DFA- $2<100 \mathrm{U} / \mathrm{L}$ had a $0 \%$ chance on POPF, compared to $36.2 \%$ in patients with DFA-2 $>100$ U/L. Elevating the threshold level led to a marginal increase in the positive predictive value, while the negative predictive value decreased substantially. Likewise, Lee et al. demonstrated in 380 patients after pancreatoduodenectomy that patients with DFA- $1<90 \mathrm{U} / \mathrm{L}$ had a $2.1 \%$ chance of POPF. [16] A recent meta-analysis also demonstrated that at a threshold of DFA- $1<100 \mathrm{U} / \mathrm{L}$ patients had a $3 \%$ risk of developing POPF, also suggesting that a low DFA threshold should be used for selective drain removal [18].

However, only few small studies compared the value of serum amylase and drain fluid amylase in the early postoperative setting. An advantage of SA is that it can be measured in 
Fig. 1 a Sensitivity and specificity of serum amylase on postoperative day 1 . b Sensitivity and specificity of drain fluid amylase on postoperative day 2

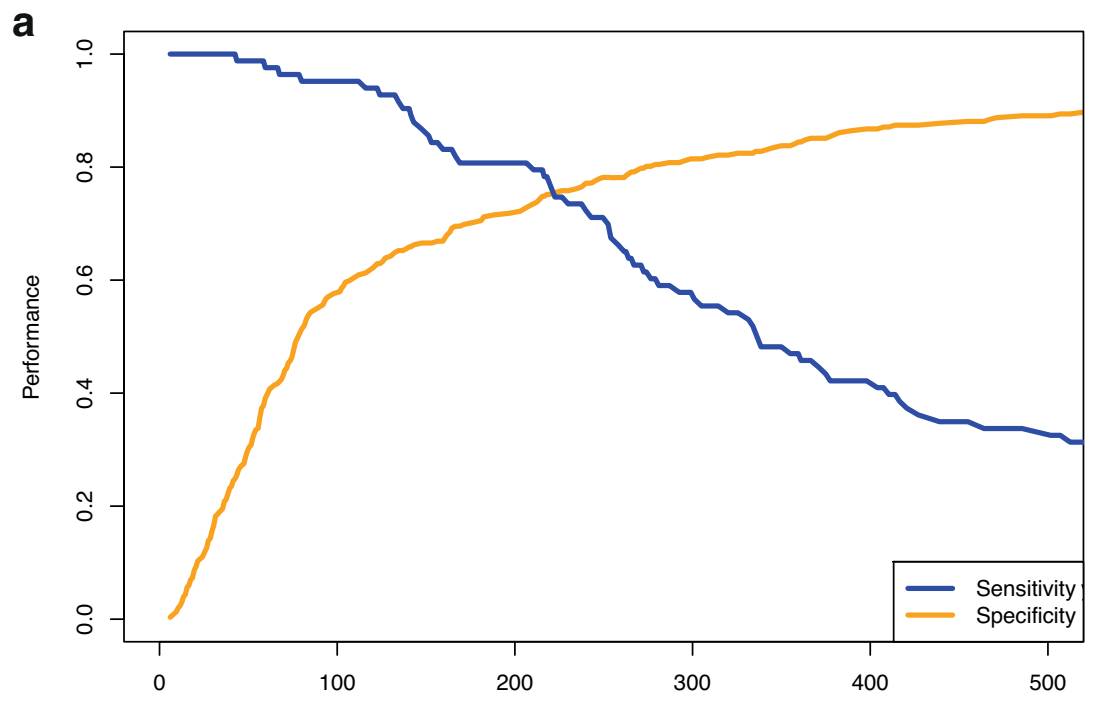

b

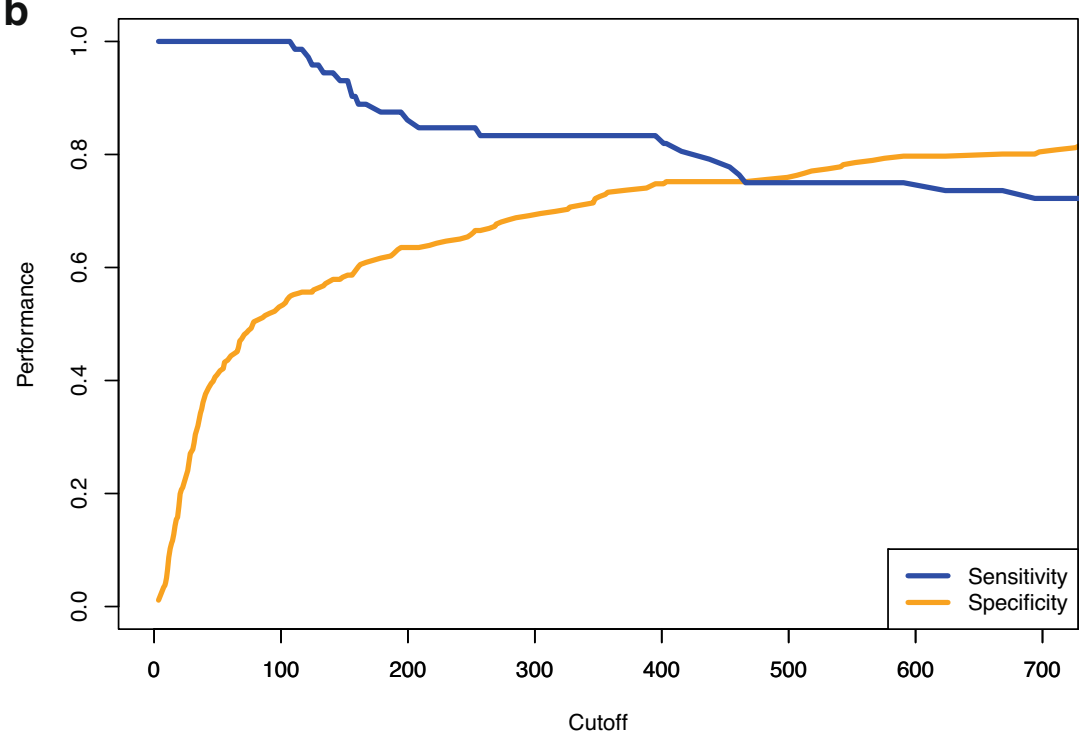

patients without surgical drains. The need for intra-operative drain placement after pancreatoduodenectomy remains debated. Three RCTs have investigated the need for surgical drainage after pancreatoduodenectomy: two RCTs found fewer complications without drains [4, 6], and one RCT was discontinued because of increased mortality in patients without drains [5]. Early drain removal has proven to lower POPF and abdominal complication rates in patients at low risk of developing POPF after pancreatoduodenectomy [7, 8]. Given the high negative predictive value of SA-1 and DFA2 , both may facilitate the selective removal of drains in patients at low risk of developing POPF. Early drain removal guided by SA might be suited to substitute DFA in practice. Blood is routinely drawn after pancreatoduodenectomy, thereby SA is an easily obtainable marker to guide drain management. Nonetheless, our data suggest that follow-up of patients at high risk of developing POPF using SA is not feasible, as it quickly normalizes in patients with elevated SA-1.

A limitation of using SA-1 at a threshold of $100 \mathrm{U} / \mathrm{L}$ is that in approximately half of the patients, postoperative drains will be left in place. These patients would require closer monitoring with a low threshold for a CT in case of clinical suspicion of pancreatic leakage or infected fluid collections. Other biomarkers and clinical parameters should be used to identify patients requiring additional CT scan imaging. For example, CRP values may facilitate the identification of patients with an elevated risk of POPF after pancreatoduodenectomy on POD 3 and 5 [24].

Diameter of the pancreatic duct, pancreatic texture, intraoperative blood loss, and other diagnoses than pancreatic adenocarcinoma or chronic pancreatitis are well-known risk factors for POPF $[1,25]$. Risk scores based on these parameters are widely applied in clinical practice to estimate the risk of 
Fig. 2 Flowchart of patients based on serum amylase on postoperative day 1 and drain fluid amylase on postoperative day 2

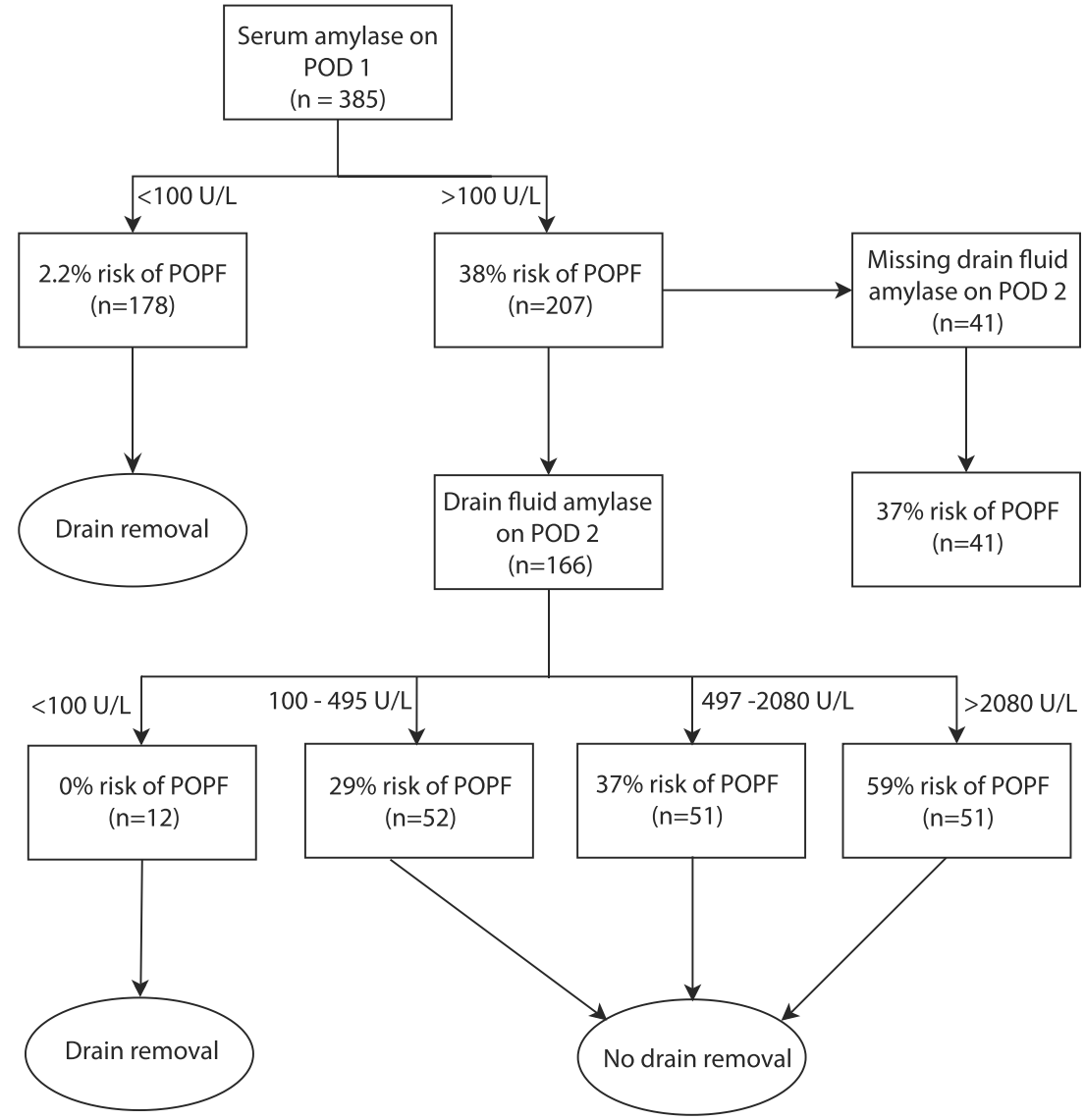

developing POPF in patients, such as the fistula risk score [1, 25]. These risk factors showed limited predictive value in combination with SA-1 and DFA-2. In the subset of patients with SA-1 and DFA-2 > $100 \mathrm{U} / \mathrm{L}$, only BMI and intraoperative blood loss were associated with POPF. Hence, SA-1 and DFA-2 could rather be used in the early postoperative setting to identify patients at high risk of POPF.

We present one of the first studies to demonstrate that the combination of SA-1 and DFA-2 might hold little additional clinical value in the early removal of drains. However, our study has certain limitations. First, due to the retrospective nature of our study, we had missing SA-1 and DFA-2 values. Furthermore, patients with high SA-1 or DFA-2 might be subjected to later drain removal and closer monitoring, which might introduce verification bias. However, generally interventions are not based on SA-1 or DFA-2 values, but rather on clinical and imaging characteristic later in the postoperative course. Finally, some of the POPF in patients with mildly elevated drain amylase may have developed because the drain was not removed, as suggested by the RCT of Bassi et al. [7].

In future research, our findings should be externally validated to analyze the generalizability of our results. Also, the feasibility of early drain removal and postoperative monitoring based on serum amylase values should be evaluated in well-designed prospective cohort studies.

\section{Conclusion}

SA-1 and DFA-2 values $<100 \mathrm{U} / \mathrm{L}$ seem to effectively rule out POPF and could be useful to guide the early removal of intra-operatively placed drains. The combination of SA-1 and DFA-2 might not facilitate early drain removal in more patients. An advantage of serum amylase measurement is that it does not require the placement of surgical.

Supplementary Information The online version contains supplementary material available at https://doi.org/10.1007/s00423-021-02192-y.

Authors' contributions J.C van Dongen participated in conceptualization, methodology, data curation, formal analysis, and writing - original draft. S. Merkens participated in data curation, formal analysis, and writing - original draft. M.H. Aziz participated in methodology and writing - reviewing and editing. B. Groot Koerkamp participated in conceptualization, methodology, and writing - reviewing and editing. C.H.J. van Eijck participated in conceptualization, methodology, supervision, and writing- reviewing and editing. 


\section{Declarations}

Conflict of interest Not applicable

Open Access This article is licensed under a Creative Commons Attribution 4.0 International License, which permits use, sharing, adaptation, distribution and reproduction in any medium or format, as long as you give appropriate credit to the original author(s) and the source, provide a link to the Creative Commons licence, and indicate if changes were made. The images or other third party material in this article are included in the article's Creative Commons licence, unless indicated otherwise in a credit line to the material. If material is not included in the article's Creative Commons licence and your intended use is not permitted by statutory regulation or exceeds the permitted use, you will need to obtain permission directly from the copyright holder. To view a copy of this licence, visit http://creativecommons.org/licenses/by/4.0/.

\section{References}

1. Callery MP, Pratt WB, Kent TS, Chaikof EL, Vollmer CM Jr (2013) A prospectively validated clinical risk score accurately predicts pancreatic fistula after pancreatoduodenectomy. J Am Coll Surg 216(1):1-14

2. Reid-Lombardo KM, Farnell MB, Crippa S, Barnett M, Maupin G, Bassi C, Traverso LW, Members of the Pancreatic Anastomotic Leak Study Group (2007) Pancreatic anastomotic leakage after pancreaticoduodenectomy in 1,507 patients: a report from the Pancreatic Anastomotic Leak Study Group. J Gastrointest Surg 11(11):1451-1458 discussion 9

3. Miller BC, Christein JD, Behrman SW, Callery MP, Drebin JA, Kent TS, Pratt WB, Lewis RS Jr, Vollmer CM Jr (2013) Assessing the impact of a fistula after a pancreaticoduodenectomy using the post-operative morbidity index. HPB (Oxford) 15(10):781-788 Epub 2013/07/23

4. Conlon KC, Labow D, Leung D, Smith A, Jarnagin W, Coit DG, Merchant N, Brennan MF (2001) Prospective randomized clinical trial of the value of intraperitoneal drainage after pancreatic resection. Ann Surg 234(4):487-493 discussion 93-4

5. Van Buren G 2nd, Bloomston M, Hughes SJ, Winter J, Behrman SW, Zyromski NJ et al (2014) A randomized prospective multicenter trial of pancreaticoduodenectomy with and without routine intraperitoneal drainage. Ann Surg 259(4):605-612 Epub 2014/01/01

6. Witzigmann H, Diener MK, Kienkotter S, Rossion I, Bruckner T, Barbel W et al (2016) No need for routine drainage after pancreatic head resection: the dual-center, randomized, controlled pandra trial (ISRCTN04937707). Ann Surg 264(3):528-537

7. Bassi C, Molinari E, Malleo G, Crippa S, Butturini G, Salvia R, Talamini G, Pederzoli P (2010) Early versus late drain removal after standard pancreatic resections: results of a prospective randomized trial. Ann Surg 252(2):207-214 Epub 2010/07/14

8. Kawai M, Tani M, Terasawa H, Ina S, Hirono S, Nishioka R, Miyazawa M, Uchiyama K, Yamaue H (2006) Early removal of prophylactic drains reduces the risk of intra-abdominal infections in patients with pancreatic head resection: prospective study for 104 consecutive patients. Ann Surg 244(1):1-7 Epub 2006/06/24
9. Beane JD, House MG, Ceppa EP, Dolejs SC, Pitt HA (2017) Variation in drain management after pancreatoduodenectomy: early versus delayed removal. Ann Surg

10. Palani Velu LK, McKay CJ, Carter CR, McMillan DC, Jamieson NB, Dickson EJ (2016) Serum amylase and C-reactive protein in risk stratification of pancreas-specific complications after pancreaticoduodenectomy. Br J Surg 103(5):553-563

11. Palani Velu LK, Chandrabalan VV, Jabbar S, McMillan DC, McKay CJ, Carter CR et al (2014) Serum amylase on the night of surgery predicts clinically significant pancreatic fistula after pancreaticoduodenectomy. HPB (Oxford) 16(7):610-619

12. Jin S, Shi XJ, Wang SY, Zhang P, Lv GY, Du XH et al (2017) Drainage fluid and serum amylase levels accurately predict development of postoperative pancreatic fistula. World J Gastroenterol 23(34):6357-6364

13. Kuhlbrey CM, Samiei N, Sick O, Makowiec F, Hopt UT, Wittel UA (2017) Pancreatitis after pancreatoduodenectomy predicts clinically relevant postoperative pancreatic fistula. J Gastrointest Surg 21(2):330-338

14. Bannone E, Andrianello S, Marchegiani G, Masini G, Malleo G, Bassi C, Salvia R (2018) Postoperative acute pancreatitis following pancreaticoduodenectomy: a determinant of fistula potentially driven by the intraoperative fluid management. Ann Surg 268(5):815-822

15. Molinari E, Bassi C, Salvia R, Butturini G, Crippa S, Talamini G, Falconi M, Pederzoli P (2007) Amylase value in drains after pancreatic resection as predictive factor of postoperative pancreatic fistula: results of a prospective study in 137 patients. Ann Surg 246(2):281-287 Epub 2007/08/02

16. Lee CW, Pitt HA, Riall TS, Ronnekleiv-Kelly SS, Israel JS, Leverson GE, Parmar AD, Kilbane EM, Hall BL, Weber SM (2014) Low drain fluid amylase predicts absence of pancreatic fistula following pancreatectomy. J Gastrointest Surg 18(11):19021910 Epub 2014/08/13

17. Israel JS, Rettammel RJ, Leverson GE, Hanks LR, Cho CS, Winslow ER, Weber SM (2014) Does postoperative drain amylase predict pancreatic fistula after pancreatectomy? J Am Coll Surg 218(5):978-987 Epub 2014/04/01

18. Giglio MC, Spalding DR, Giakoustidis A, Zarzavadjian Le Bian A, Jiao LR, Habib NA et al (2016) Meta-analysis of drain amylase content on postoperative day 1 as a predictor of pancreatic fistula following pancreatic resection. Br J Surg 103(4):328-336 Epub 2016/01/23

19. McMillan MT, Malleo G, Bassi C, Butturini G, Salvia R, Roses RE et al (2015) Drain management after pancreatoduodenectomy: reappraisal of a prospective randomized trial using risk stratification. J Am Coll Surg 221(4):798-809

20. Bassi C, Marchegiani G, Dervenis C, Sarr M, Abu Hilal M, Adham M, Allen P, Andersson R, Asbun HJ, Besselink MG, Conlon K, del Chiaro M, Falconi M, Fernandez-Cruz L, Fernandez-del Castillo C, Fingerhut A, Friess H, Gouma DJ, Hackert T, Izbicki J, Lillemoe KD, Neoptolemos JP, Olah A, Schulick R, Shrikhande SV, Takada T, Takaori K, Traverso W, Vollmer CR, Wolfgang CL, Yeo CJ, Salvia R, Buchler M, International Study Group on Pancreatic Surgery (ISGPS) (2017) The 2016 update of the International Study Group (ISGPS) definition and grading of postoperative pancreatic fistula: 11 Years After. Surgery. 161(3):584-591 Epub 2017/01/04

21. Wente MN, Bassi C, Dervenis C, Fingerhut A, Gouma DJ, Izbicki JR, Neoptolemos JP, Padbury RT, Sarr MG, Traverso LW, Yeo CJ, Büchler MW (2007) Delayed gastric emptying (DGE) after pancreatic surgery: a suggested definition by the International Study 
Group of Pancreatic Surgery (ISGPS). Surgery. 142(5):761-768 Epub 2007/11/06

22. Wente MN, Veit JA, Bassi C, Dervenis C, Fingerhut A, Gouma DJ, Izbicki JR, Neoptolemos JP, Padbury RT, Sarr MG, Yeo CJ, Büchler MW (2007) Postpancreatectomy hemorrhage (PPH): an International Study Group of Pancreatic Surgery (ISGPS) definition. Surgery. 142(1):20-25 Epub 2007/07/17

23. Dindo D, Demartines N, Clavien PA (2004) Classification of surgical complications: a new proposal with evaluation in a cohort of 6336 patients and results of a survey. Ann Surg 240(2):205-213

24. van Dongen JC, Smits FJ, van Santvoort HC, Molenaar IQ, Busch OR, Besselink MG et al (2020) C-reactive protein is superior to white blood cell count for early detection of complications after pancreatoduodenectomy: a retrospective multicenter cohort study. HPB (Oxford)

25. Miller BC, Christein JD, Behrman SW, Drebin JA, Pratt WB, Callery MP, Vollmer CM Jr (2014) A multi-institutional external validation of the fistula risk score for pancreatoduodenectomy. J Gastrointest Surg 18(1):172-179 discussion 9-80

Publisher's note Springer Nature remains neutral with regard to jurisdictional claims in published maps and institutional affiliations. 